\title{
O conceito de geração nas teorias sobre juventude ${ }^{1}$
}

\section{Carles Feixa ${ }^{2}$ \\ Carmem Leccardi ${ }^{3}$}

Resumo: Desde Augusto Comte e Karl Mannheim (mas também desde José Ortega y Gasset e Antonio Gramsci), o conceito de geração tem sido um tema relevante nas ciências humanas e sociais. Como metáfora para a construção social do tempo, tem sido uma das categorias mais influentes não só no debate teórico, mas também no impacto público das pesquisas sobre juventude. Mesmo que o uso e abuso do conceito esteja enraizado no contexto europeu no período entre a Grande Guerra e a Segunda Guerra Mundial, tem sido relevante nos debates ideológicos e políticos de outras regiões. Este artigo representa uma tentativa de repensar o conceito de geração a partir de uma perspectiva histórica, destacando-se sua relevância para os debates contemporâneos sobre juventude.

Palavras-chave: geração, juventude, sociologia, Itália, Espanha.

\section{Introdução}

\begin{abstract}
Assim como os conceitos de "nação" ou "classe", o termo geração é uma expressão "performativa" (que cria uma entidade para nomeá-la) - uma chamada ou convocação para uma batalha nas fileiras do imaginário, ou mais precisamente postulado, da comunidade.

Zygmunt Bauman (2007: 370, tradução nossa).
\end{abstract}

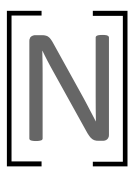

o pensamento social contemporâneo, a noção de geração foi desenvolvida em três momentos históricos, que correspondem a três quadros sociopolíticos particulares: durante os anos 1920, no período entreguerras, as bases filosóficas são formuladas em torno da noção de "revezamento geracional" 4 (sucessão e coexistência de gerações), existindo um consenso geral sobre este aspecto (Ortega y Gasset, 1923; Mannheim, 1928). Durante os anos 1960, na época do protesto, uma teoria em torno da noção de "problema geracional"5 (e conflito geracional) é funda-
1. Este artigo resulta de um trabalho apresentado no primeiro Fórum de Sociologia da ISA

(Barcelona, Espanha, 5-8 setembro de 2008): “Growing up in a liquid world: Youth questions and public debates", organizado pelos autores.

Foi traduzido do inglês para o português por Lucélia de Moraes Braga Bassalo, com revisão de Wivian Weller.

2. Professor de antropologia da Universidade de Lleida, Espanha. feixa@geosoc.udl.es

3. Professora de sociologia da cultura da Universidade Milano-Bicocca. carmen.leccardi@unimib.it

4. Generation relay, no original. NdaT

5. Generation gap, no original. NdaT 
6. Generation lap, no original. NdaT mentada sobre a teoria do conflito (Feuer, 1968; Mendel 1969). A partir de meados dos anos 1990, com a emergência do sociedade em rede, surge uma nova teoria em torno da noção de "sobreposição geracional". ${ }^{6}$ Isto corresponde à situação em que os jovens são mais habilidosos do que as gerações anteriores em um centro de inovação para a sociedade: a tecnologia digital (Tapscott 1998; Chisholm, 2005).

No ano de 2007, em uma conferência pronunciada em Barcelona, Zygmunt Bauman evocou os escritos sobre gerações de José Ortega y Gasset. O sociólogo polonês lembrou que a principal contribuição do filósofo espanhol não se constituiu na ideia de "sucessão" entre gerações (uma ideia muito presente no pensamento e no senso comum da época e, na verdade, de todos os tempos), mas de "coincidência" e "sobreposição", isto é, de coexistência parcial entre gerações:

As fronteiras que separam as gerações não são claramente definidas, não podem deixar de ser ambíguas e atravessadas e, definitivamente não podem ser ignoradas (Bauman, 2007: 373).

No mesmo congresso, o sociólogo francês Michel Maffesoli abordou o tema das gerações que vivem juntas, a partir da noção de "hospitalidade". Evocando a metáfora da "tribo", que se tornou famosa, lembrou que a convivência entre anfitriões e convidados (adultos e jovens) torna-se mais frutífera quanto mais ela se baseia no prazer da competição ou do jogo:

As gerações jovens vivem estes valores hedonistas em uma forma paroxística. Contudo, através de um processo de contaminação, é o corpo social que acaba sendo afetado (Maffesoli, 2007: 378).

Desde que tivemos a oportunidade de ouvir o diálogo entre estes dois renomados sociólogos, decidimos analisar o papel do conceito de geração na história das teorias sobre juventude. Começaremos por revisar as raízes do pensamento sociológico relativos ao conceito de geração, revendo a posição de alguns pensadores clássicos. Mais adiante, traremos à tona o debate intelectual e social em torno das gerações a partir de pontos de vista políticos e acadêmicos, em dois locais onde o conceito tem sido relevante: Itália e Espanha. 
Jovens que experienciam os mesmos problemas históricos concretos, pode-se dizer, fazem parte da mesma geração.

Karl Mannheim (1928).
O conceito de geração pode ser delimitado em termos ${ }^{7}$ sociológicos pelas referências a Comte e Dilthey, dois autores do século XIX que, apesar das diferenças entre suas abordagens teóricas, lançam as bases para reflexões subsequentes no século XX. Em seguida, pode ser considerado à luz do pensamento de Mannheim, visto como o fundador da abordagem moderna do tema gerações; posteriormente, de forma sumária, a partir de Ortega y Gasset e Gramsci e, finalmente, pela teoria apresentada por Abrams (1982). ${ }^{8}$ As duas primeiras teorias - uma positivista (Comte), outra histórico-romântica (Dilthey) - são as que Mannheim (1928) usou como base para as suas reflexões sobre gerações. Mannheim, além da importância dos demais pensadores, será referência obrigatória para a análise das relações entre sociologia e história.

\subsection{A visão positivista de Augusto Comte}

No início da sociologia, uma concepção mecânica e exteriorizada do tempo das gerações foi apresentada por Comte (1998). Essa era uma teoria totalmente interna ao positivismo comteano, a esforçar-se para identificar um tempo quantitativo e objetivamente mensurável como critério para o progresso linear. Com base no postulado entre progresso e sucessão das gerações, Comte afirmou que o ritmo pode ser calculado simplesmente pela medição do tempo médio necessário para que uma geração seja substituída - na vida pública - por uma nova (30 anos, de acordo com Comte). ${ }^{9}$ Progresso, além disso, é o resultado do entrelaçamento equilibrado entre as mudanças produzidas pela nova geração e a estabilidade mantida pelas gerações mais velhas. A palavra-chave que Comte procura para a objetividade histórica é continuidade. Neste quadro analítico - e ao contrário do lluminismo -, o progresso é identificado com as novas gerações, o que não significa desvalorização do passado, que coincide com as gerações mais velhas. O tempo social é "biologizado". De modo semeIhante ao organismo humano, também o organismo social é sujeito ao desgaste. Mas, para este, as "partes" podem ser facilmente substituídas: as novas gerações tomarão o lugar das antigas. O conflito entre gerações
7. Como bem se sabe, o termo "geração" é usado de diferentes modos por diferentes disciplinas (por exemplo, sociologia, etnologia e demografia). Em termos de pluralidade de significados, cf. particularmente Kertzer (1983) e Attias-Donfut (1991). Em sociologia, o conceito de geração - afora os sentidos provenientes de diferentes aplicações realizadas por autores individualmente - diz respeito à "duração comum".

8. Os autores aqui apresentados buscaram mostrar a conexão entre tempo individual e tempo social - uma relação crucial na pesquisa geracional.

9. O lapso de tempo corresponde a uma duração média da vida individual produtiva. 
pode somente acontecer se a duração da vida humana tornar-se excessivamente longa, frustrando as novas gerações e seu "instinto inovador", de descobrir espaços de expressão de si (se a vida fosse excessivamente breve, a predominância deste instinto criaria um desequilíbrio social que inevitavelmente romperia o ritmo do progresso). Assim, através de sua reflexão sobre gerações, Comte propôs uma lei geral sobre o ritmo da história. Leis biológicas, relacionadas com a duração média da vida e da sucessão das gerações, a base da "objetividade" do ritmo.

\subsection{A abordagem historicista de Dilthey}

A visão matemática e quantitativa do tempo das gerações tal como apresentada pela teoria de Comte foi radicalmente recusada pela abordagem histórico-romântica. Esta última enfatizou a conexão obtida, em termos qualitativos, entre os ritmos da história e os ritmos das gerações. Nesta perspectiva, o que mais importa é a qualidade dos vínculos que os indivíduos das gerações mantêm em conjunto. Em consonância com esta abordagem, Dilthey (1989) argumentou que a questão das gerações exigiu a análise do tempo da experiência medido exclusivamente em termos qualitativos.

Para o autor, ao contrário de Comte, a sucessão das gerações não é importante. As gerações - asseverou - são definidas em termos de relações de contemporaneidade e consistem num conjunto de pessoas sujeitas em seus anos de maleabilidade máxima a influências históricas comuns (intelectuais, sociais e políticas). Em outras palavras: consiste de pessoas que partilham o mesmo conjunto de experiências, o mesmo "tempo qualitativo". A formação das gerações foi consequentemente baseada em uma temporalidade concreta, constituída de acontecimentos e experiências compartilhadas.

Em termos mais gerais, para Dilthey as experiências históricas delimitam o pertencimento a uma geração, porque se fundam na existência humana. Esta visão só é compreensível se tivermos em mente a interpretação ampla que Dilthey atribuiu à temporalidade. Ele opôs o tempo humano - concreto e contínuo - ao tempo abstrato e descontínuo da natureza. A continuidade do padrão provém da capacidade da mente humana - ao contrário da qualidade do tempo que a natureza possui - de transcender o tempo percorrido e construir acontecimentos individuais dentro de um todo homogêneo e coerente. 
Para Dilthey, ademais, a vida humana é uma temporalidade (noção posteriormente retomada por Heidegger). A conexão entre o tempo humano e o tempo histórico provém principalmente da capacidade de moldar, uniformizar o tempo pessoal e interpretá-lo num todo significativo. Mas ela também está intimamente associada à historicidade decorrente de um ponto de vista adicional. É a história que possibilita de fato à mente humana emancipar-se da tradição da natureza. De acordo com Dilthey, o tempo desta última, ao contrário do tempo humano, é formado por uma série de eventos descontínuos de valor igual, destituída de uma estrutura de passado, presente e futuro. A natureza não tem história e é, consequentemente, teoricamente irrelevante.

\subsection{A formulação sociológica de Mannheim}

A análise de Mannheim sobre gerações (1952) foi - como bem se sabe um divisor de águas na história sociológica do conceito. Quando Mannheim desenvolveu sua teoria das gerações - fazendo inter alia uma comparação com os amplos movimentos coletivos do século $X X^{10}$ - teve um duplo objetivo: distanciar-se do positivismo - a abordagem biológica das gerações -, bem como da perspectiva romântico-histórica. Além disso, seu maior interesse foi o de incluir as gerações em sua pesquisa sobre as bases sociais e existenciais do conhecimento em relação ao processo histórico-social.

Neste contexto, Mannheim considerou as gerações como dimensão analítica profícua para o estudo da dinâmica das mudanças sociais (sem recorrer ao conceito de classe e ao núcleo da noção marxista de interesses econômicos), de "estilos de pensamento" de uma época e da ação. Estes, de acordo com Mannheim, foram produtos específicos - capazes de produzir mudanças sociais - da colisão entre o tempo biográfico e o tempo histórico. Ao mesmo tempo, as gerações podem ser consideradas o resultado de descontinuidades históricas e, portanto, de mudanças. Em outras palavras: o que forma uma geração não é uma data de nascimento comum - a "demarcação geracional" é algo "apenas potencial" (Mannheim, 1952) - mas é a parte do processo histórico que jovens da mesma idade-classe de fato compartilham (a geração atual).

Há dois componentes centrais nesta partilha (do qual surge o "laço geracional"): por um lado, a presença de eventos que quebram a continuidade histórica e demarcam o "antes" e o "depois" na vida coletiva; de outro, o
10. Quando Karl Mannheim escreveu seu ensaio sobre gerações, movimentos juvenis alemães, contando com a participação de dezenas de milhares de membros, assumiram o papel de condução política na vida nacional alemã. 
fato que estas descontinuidades são experienciadas pelos membros de um grupo etário em uma conexão constitutiva particular, quando o processo de socialização não foi concluído, pelo menos no seu período crucial, e os esquemas utilizados para interpretar a realidade não são ainda totalmente rígidos ou - como coloca Mannheim - quando essas experiências históricas são "primeiras impressões" ou "experiências juvenis".

$\mathrm{Na}$ "unidade geracional", por seu turno, elaboram-se vínculos de diferentes maneiras e formas de acordo com os grupos concretos aos quais seus membros pertencem. Através do conceito de geração, os longos tempos da história são fixados em relação aos tempos da existência humana e entrelaçados com a mudança social.

\subsection{A análise de Abrams:}

Gerações, tempo histórico e identidade

O sociólogo inglês Philip Abrams (1982) ampliou a perspectiva lançada por Mannheim em circunstâncias diferentes. Cinquenta anos depois da teoria original de Mannheim, Abrams aprofundou e expandiu a noção históricosocial de geração ao relacioná-la à identidade. Sua intenção foi lançar luzes sobre a íntima relação entre o tempo individual e o tempo social, enfatizando sua filiação com registros históricos.

O ponto de partida de Abrams foi sua convicção de que a individualidade e a sociedade são construções históricas. É portanto necessário analisar suas interconexões e, simultaneamente, suas mudanças ao longo do tempo. Identidades - considerado o elo entre as duas dimensões individual e social - devem, por seu turno, ser investigadas dentro de um modelo de referência histórico-social. Após rejeitar a definição de identidade, amparada tanto em termos psicológicos como "sociolinguísticos" - ou seja, associada mecanicamente à execução de papéis -, Abrams definiu-a como consciência do entrelaçamento da história individual e da história social.

A relação entre estas duas dimensões da história emerge claramente se for feita referência ao tempo social. É dentro deste último, de fato, que a sociedade e a identidade geram-se reciprocamente. Mas de que forma esta conexão entre identidade e geração é realizada? Para Abrams uma geração, no sentido sociológico, é o período de tempo durante o qual a identidade é construída a partir de recursos e significados que estão socialmente e histo- 
ricamente disponíveis. Assim, novas gerações criam novas identidades e novas possibilidades para a ação.

Sociologicamente, portanto, as gerações não surgem da cadência temporal estabelecida por uma sucessão de gerações biológicas. Em outras palavras: não há padronização do tempo para medir ou prognosticar seu ritmo. Do ponto de vista sociológico, uma geração pode ter dez anos, ou como aconteceu nas sociedades pré-modernas, vários séculos. Pode incluir uma pluralidade de gerações biográficas ou, como na história de muitas sociedades tradicionais, apresentar apenas uma geração sociológica. Elas cessam quando novos e grandes eventos históricos - ou, mais frequentemente, quando lentos e não catastróficos processos econômicos, políticos e de natureza cultural - tornam o sistema anterior e as experiências sociais a ela relacionadas sem significado.

Consequentemente, para Abrams ou para Mannheim, o início de uma geração é marcado por descontinuidades importantes até então dominantes em determinada época histórica e institucional. Novamente, o tempo histórico-social e seus ritmos é visto como central para a definição das novas gerações e identidades sociais. Mais precisamente: é o processo de mudança que produz o anterior e o posterior.

Nesta perspectiva, gerações é o lugar em que dois tempos diferentes - o do curso da vida, e o da experiência histórica - são sincronizados. O tempo biográfico e o tempo histórico fundem-se e transformam-se criando desse modo uma geração social.

3. O debate sobre gerações na Itália

De fato, pessoas mais velhas administram a vida, mas não pretendem direcioná-la, deixando a direção para os jovens; também a "ficção" é importante nestas coisas...

Antônio Gramsci (1930)

\subsection{Consciência geracional}

Nos últimos anos, a concepção genealógica de geração - isto é, definida em termos de descendência - ganhou mais terreno na Itália. Nesta estrutura, o conceito de consciência geracional assumiu grande importância por duas 
11. Para uma discussão detalhada, cf. Attius Donfut (1988, Parte 3, cap. 11).
12. Na Itália, Paul Jedlowski é o autor que mais trabalhou, em termos sociológicos, sobre o tópico da experiência. Cf. Jedlowski (1994). razões principais: por um lado, porque permite que o tempo biográfico e o tempo social sejam interligados; de outro, porque permite que a dimensão da reflexividade seja introduzida na análise da dinâmica geracional e nos processos de mudança social. No que diz respeito à consciência geracional, pode, por exemplo, mostrar os modos pelos quais as continuidades e descontinuidades histórico-sociais, como reprocessadas pelos indivíduos, se configuram como base para a construção dos laços sociais entre diferentes gerações.

Durante a década de 1990, este aspecto atraiu particular atenção no Mezzogiorno da Itália, região marcada econômica e socialmente por intensos processos de mudança, mas, culturalmente, por formas de continuidade. Analisado a partir desse quadro, constatou-se, por exemplo, mudanças na biografia feminina e nos processos pelos quais jovens mulheres no sul do país - com muito mais educação e habilidade do que as gerações anteriores de mulheres - desenvolveram laços intergeracionais em termos de genealogias femininas (Bell, 1999; Siebet, 1991).

Neste contexto, o conceito de consciência geracional tem mais dois componentes: ${ }^{11}$ em primeiro lugar, a historicidade e, em segundo, o vínculo estreito com a dimensão da experiência. O primeiro aspecto diz respeito à habilidade de situar-se num quadro histórico com base na consciência de que existe um passado e um futuro que se prolongam para além de sua própria experiência, que relacionam a própria vida com as gerações anteriores e com as gerações que virão. Embora as gerações por si mesmas ajudem a estruturar o tempo social - diferentes gerações personificam coletivamente o passado, o presente e o futuro - a consciência geracional possibilita que o vinculo seja elaborado subjetivamente. Localizar-se a si mesmo no fluxo das gerações não significa somente relacionar-se com o tempo social, mas também inscrever a própria existência, a própria história, numa história mais ampla na qual ela se inclui.

O segundo aspecto destaca a capacidade de a consciência geracional promover um contato profundo com o tempo da vida - uma dimensão crucial que é a base para o processamento da experiência (de acordo com a etimologia do termo: ex-per-ire, "passar através de"). ${ }^{12}$ Este processo de interpretação do tempo biográfico estimulado pela consciência geracional possibilita o crescimento do self como entidade separada e única. Esta singularidade é medida em função do tempo histórico e suas mudanças como incorporadas pelas gerações anteriores: por exemplo, mediante a 
análise das diferenças/similaridades de como o futuro é dirigido e a identidade construída. Em outras palavras: consciência geracional - uma dimensão que, por sua natureza, enfatiza uma abordagem reflexiva - envolve a consciência de sua proximidade/distância de outras gerações familiares. Quando esta consciência está presente, ${ }^{13}$ as relações intergeracionais tornam-se domínio da elaboração subjetiva. Consciência de seu próprio tempo de vida significa, consequentemente, estar consciente de que essas relações são atravessadas e construídas num significativo e maior período de tempo. Devido a mediação das relações afetivas na família, esta relação com a temporalidade histórica e social adquire ressonâncias pessoais. Adquire o registro do "conhecido" e também fala a linguagem das emoções. História torna-se memória coletiva (Halbwachs, 1950, 1975), e a memória coletiva sustenta e cria a memória pessoal.

Já foi mencionada a relação entre geração e reflexividade. Esta relação pode ser esclarecida considerando a natureza inconsciente e involuntária de uma parte substancial da transmissão intergeracional - um aspecto que também atraiu a atenção de Karl Mannheim (1952). É por causa destes traços de desconhecimento e involuntariedade que os conteúdos transmitidos adquirem força e influência, tendendo a se estabilizar como uma concepção "natural", uma concepção do mundo que os recebe. A este respeito, Isabelle Bertaux-Wiame (1988), em seus estudos sobre memórias de família, mostra a existência de uma "memória longa", a qual os membros da família levam consigo de forma involuntária. Esta memória não é formada somente pelas lembranças pessoais, mas também daquelas transmitidas pelas gerações anteriores e que se tornaram uma parte integrante do itinerário do que é assimilado mais ou menos conscientemente. A influência desta "memória longa" é ainda mais persistente pela afetividade natural da memória familiar, que a constitui íntima e profundamente (Namer, 1988). Esta ação consolida os laços sociais entre os membros do grupo familiar, cuja coesão é, portanto, reforçada. Graças a isto, a memória familiar personifica a continuidade entre as gerações; previne a exacerbação das diferenças; protege a unidade do grupo. Além disso, através da afetividade, o caráter normativo da transmissão é sustentado e as "imagens de mundo" nela contida são fortalecidas.

Consciência geracional permite examinar criticamente esta memória, deslocando estes conteúdos da escuridão para a luz. Estes últimos podem, assim, ser submetidos à reflexão, problematização e porventura ser rejeitados. Isto pode assim ser executado numa seleção consciente de critérios,
13. Hoje, dois fatores - um favorável, outro contrário - estão simultaneamente presentes no trabalho que considera a consciência geracional. Por um lado, favorecendo consciência geracional, está a existência da sociedade multigeracional em que diferentes gerações convivem (sem precedentes na história humana); de outro, está obstruída pela velocidade das mudanças, que frustram o sentido da continuidade temporal em desenvolvimento. 
14. Esta questão com relação ao Mezzogiorno da Itália foi analisada por Leccardi (2006). cujas bases da memória em questão foram construídas e em seguida transmitidas (Cavalli, 1991). Se a memória coletiva familiar tende à transmissão de uma visão desproblematizadora do passado, esta visão pode ser criticamente questionada através do exercício reflexivo que acompanha a consciência geracional. Também por força desta relação crítica com a memória, a consciência geracional favorece o crescimento da consciência de si como uma pessoa separada e única. Mas esta singularidade - para repetir - é medida em função do tempo histórico e de suas mudanças encarnadas pelas diferentes gerações de famílias.

Assim a consciência geracional envolve deliberadamente a assunção de continuidades e descontinuidades intergeracionais e a possibilidade de arranjálas reflexivamente junto às bases do processamento do tempo biográfico. Em outras palavras: consciência geracional é uma poderosa ferramenta para converter as diferenças entre gerações em bases de reconhecimento de si. ${ }^{14}$

\subsection{Da consciência geracional a genealogia}

Embora a consciência geracional envolva a comparação com gerações anteriores, isto não significa que é construída em oposição a essas. Especialmente para gerações de mulheres da mesma família, a ideia de genealogia - entendida como continuidade na mudança - assume grande importância. As gerações de avós e mães personificam uma época que suas filhas não viveram; mais tarde exploram os limites de suas identidades comparando seu próprio tempo biográfico com o de outras gerações de mulheres. Ademais, a memória familiar, das quais avós e mães são guardiãs, permite que as filhas avaliem o caminho percorrido pelas gerações de mulheres imediatamente anterior à delas, bem como medir a distancia ainda existente e a ser coberta.

O tempo vivido por outras gerações de mulheres, e reunido por mulheres jovens em histórias, memórias e experiências, que como filhas testemunharam, as conecta no tempo histórico e social. Na avaliação de proximidade e distância, de similaridades e diferenças na forma como o significado é produzido e a subjetividade é construída, elas adquirem ferramentas para descobrir a singularidade de suas vidas enquanto perdurar a compreensão de que pertencem a um mundo compartilhado: o da família.

Consequentemente embora ambas - geração e genealogia - sejam construídas através da referência do tempo, somente a última representa uma dimensão que pode ser chamada de "personificada", isso em função da 
conexão física que se deve à descendência. A relação corporal impede que o modelo genealógico "perca-se" num circuito temporal abstrato sem conexão com a vida de mulheres de "carne e sangue" que conheceram a visibilidade e o poder diferenciados de homens e mulheres na vida pública.

Além disso, o aspecto "personificado" da genealogia atua em outro nível, no qual gerações de mulheres mantiveram diferentes relações com seus corpos e com seus códigos simbólicos. No Mezzogiorno, por exemplo, as autorrepresentações de mulheres jovens carregam as marcas de corpos silenciados de suas avós e dos corpos "negociados" de suas mães. Estas autorrepresentações são capazes de reduzir o peso da gravidez, mas elas ainda não as intitulam sujeitos completos da esfera pública e privada (Siebert, 1991).

Libertadas do "silêncio" imposto aos corpos femininos pelas gerações de mulheres que as antecederam, jovens mulheres do sul não raramente têm sentimentos ambivalentes acerca de sua sexualidade - sentimentos que podem ser interpretados como resultantes de suas relações com as experiências das gerações anteriores -, em outras palavras, da genealogia feminina na qual estão inseridas. A dimensão genealógica constitui um quadro de referência no qual suas identidades são construídas e a subjetividade toma forma.

Em suma: ao "dar corpo" ao tempo, a genealogia materializa o pertencimento geracional. Através da genealogia, "ser mulher" no tempo e no espaço presente recebe luz da consciência que as experiências das gerações anteriores de mulheres lançaram e que devem ser localizadas e compreendidas no devido contexto histórico. Reconhecer-se numa genealogia feminina é, portanto, olhar em direção à dimensão geracional para além da perspectiva de Mannheim, com sua identificação dos eventos histórico-políticos cruciais, capazes de marcar a descontinuidade tanto na sociedade como nas biografias individuais. A dimensão genealógica implica, por sua vez, na consciência de que as mudanças biográficas têm seu próprio lugar determinado pela descendência. Ao mesmo tempo, requer elaborar subjetivamente as diferenças que assim surgiram (Bell, 1999). $\mathrm{Na}$ abordagem genealógica, a dimensão temporal que molda as gerações na encruzilhada entre os aspectos coletivos e individuais do tempo compreende descontinuidades dentro de uma visão que não procura "origens", mas, em seu lugar, considera os movimentos, interconexões, ${ }^{15}$ contingências e diferenças, dentro de um quadro de referência que enfatiza e "personifica" o aspecto do tempo.
15. Como a abordagem genealógica desenvolvida por Foucault, cf., por exemplo, o ensaio sobre "Nietzsche, genealogy, history", em Foucault (1971). Cf., também, Michon (2002). 
16. Generation gap, no original. $\mathrm{NdaT}$

17. O autor faz referência ao regime republicano instituído na Espanha a 14.04.1931, em decorrência do revés eleitoral sofrido por Afonso XIII nas eleições municipais daquele mesmo ano, após a renúncia do general Primo de Rivera. NdoE

18. A conceituação de Ortega y Gasset é contemporânea à de Mannheim, embora sua concepção tenha sido formulada de modo totalmente independente. A teoria de gerações de Ortega não é exposta em um único texto, como aconteceu com Mannheim, mas se desenvolve como um fio condutor através de toda a sua obra filosófica: ele prepara inicialmente um apontamento para algumas conferências proferidas em 1914, desenvolvendo sua primeira formulação na universidade em 1920-1921, e publicou, em 1923, um texto

introdutório em seu livro El tema de nuestro tiempo sob o título La idea de las generaciones (1966). Sua formulação foi retomada em algumas conferências importantes ocorridas em Buenos Aires, em 1928, e publicada postumamente com o título Juventud,

\section{O debate sobre gerações na Espanha}

Pode-se dizer que a noção de "geração" é uma das escassas contribuições da Espanha para o pensamento sociológico universal, considerando que a epígrafe "geração" do International Encyclopedia of the Social Sciences foi escrita pelo filósofo Julián Marías (1968), discípulo de José Ortega y Gasset e pai de Javier Marías, o mais conhecido romancista espanhol da atualidade. Isto pode ser afirmado por três motivos: 1. A importância da geração literária de 98 (1898 foi o ano da guerra com os Estados Unidos, na qual a Espanha perdeu Cuba, sua última colônia nas Américas, e que deu lugar a uma profunda reflexão sobre a "crise"); 2 . O impacto nacional e internacional do trabalho de Ortega y Gasset (o mais importante filósofo espanhol do século XX); e 3. Um profundo "conflito geracional"16 provocado pela Guerra Civil Espanhola (a partir da qual surgiu uma ditadura que originou-se da luta de classes pela sucessão geracional como motor da história).

\subsection{Ortega y Gasset:}

\section{Gerações como conceito-chave na história}

Em 1923, Ortega y Gasset publicou La idea de las generaciones, no qual defendeu que as pessoas nascidas em um mesmo tempo partilham da mesma "sensibilidade vital" que se opõe às gerações anteriores e mais recentes e que define sua "missão histórica". O filósofo foi educado como um pensador liberal na escola germânica e teve um grande impacto na América Latina, apoiando a II República embora, mais tarde, tenha dela se afastado pelos excessos cometidos. ${ }^{17}$ Ele foi o mais importante intelectual espanhol da primeira metade do século $X X$, formando diferentes gerações de pensadores e intervindo nos debates públicos com a imprensa. ${ }^{18}$

No texto mencionado, a ideia de geração foi considerada como o "conceito mais importante da história". De fato, o autor estava argumentando contra a influência da Revolução Soviética e do fascismo, mas, simultaneamente, tornou-se o paradigma da força de regeneração dos jovens. Os jovens estavam substituindo o proletariado como sujeito emergente e a sucessão geracional foi substituída pela luta de classes como motor da mudança. Mais tarde, o filósofo publicou El método histórico de las generaciones que permitiu a compreensão do curso da história, partindo da ideia de que cada relevo geracional tem lugar a cada 15 anos. Todavia, como Bauman (2007) observou, a ideia central de Ortega y Gasset não é de sucessão mas de sobreposição: nem todas as pessoas contemporâneas podem ser conside- 
radas contemporâneas. Por esta razão, há tempos da velhice - "acumulativo" - e tempos da juventude - "eliminativos" ou "polêmicos". De acordo com a visão elitista do autor, a relação é estabelecida entre as minorias e as massas: quando alguns indivíduos vivem em tempos de crise, captam uma nova "sensibilidade vital" e pela "primeira vez eles têm novos pensamentos com plena clareza", tornando-se uma geração decisiva para seus pares, porque podem conectar-se com as mudanças valorizadas. Mas Ortega y Gasset não analisou como os grupos de idade desenvolvem uma consciência comum e agem como força histórica coerente. ${ }^{19}$

\subsection{Marías e Aranguren: \\ O método histórico das gerações}

Na Espanha, a teoria de Ortega y Gasset foi desenvolvida por seus discípulos durante o regime de Franco, ainda que sua aplicação tenha sido no mundo da criação artística e literária. O historiador Pedro Lain Entralgo publicou, em 1945, Las generaciones en la história aplicando a concepção de Ortega y Gasset aos romancistas de 1898. Em 1949, o filósofo Julián Marías publicou El método histórico de las generaciones, comparando a contribuição de Ortega y Gasset com a de outros autores (Comte, Mill, Ferrari, Dilthey, Ranke) e pensadores contemporâneos (Mentré, Pinder, Petersen, Mannheim, Croce \& Huizinga, entre outros). É significativo que ambos os livros apareceram no pós-Guerra, momento mais inflexível do regime de Franco: era uma forma velada de evitar a discussão sobre o conflito social, mas, ao mesmo tempo, de permitir a abertura de um debate no âmbito do pensamento sociológico internacional. ${ }^{20}$

Em 1960, o filósofo Jose L. López Aranguren publicou um qualificado ensaio: La juventud europea y otros ensayos. Embora tenha influenciado os jovens da década de 1960, ele de fato se referia à juventude espanhola do pós-Guerra, a geração que se tornou madura entre 1945 e 1960. O texto está na corrente do pensamento de Ortega y Gasset, que Aranguren conheceu quando ainda estudante. Mas, ao contrário de Lain e Marías, o autor não permaneceu na reflexão filosófica abstrata: ele chegou à realidade histórica e social através de resultados de informações empíricas dos primeiros estudos sobre jovens oriundos de pesquisas de opinião, bem como através de seu conhecimento direto como professor universitário e dissidente cristão (e passou a nomear os seus estudos como "trabalho de campo"). Isto o levou a postular o fechamento do conflito entre a minoridade e a massa assim como à critica dos 15 anos como tempo de cuerpo (1996). Tais análises são desenvolvidas em 1933 como ensaio central de seu livro $E I$ torno a Galileo sob o título El método histórico de las generaciones (1970). Embora este último trabalho tenha sido publicado após o lançamento do artigo de Mannheim, não nos parece que Ortega estivesse familiarizado com o texto do autor alemão (assim como o autor alemão não demonstra conhecer o trabalho de Ortega y Gasset). Cf. Sánchez de la Yncera (1993).

19. O trabalho de Ortega y Gasset teve grande repercussão no pensamento sociológico de todo o mundo antes da Segunda Guerra Mundial, especialmente na Europa

mediterrânea, na Alemanha e na América Latina. Seu trabalho também foi retomado, por alguns autores, nas décadas 1960 e 1970 , notadamente na análise da revolta juvenil. Mereceu um artigo crítico em um volume sobre a sucessão geracional organizado pelo Partido Comunista da União Soviética (Moskvichov, 1977), assim como uma sistematização teórica desenvolvida por um sociólogo sulafricano (cf. Jansen, 1977). No entanto, nas últimas três décadas, desapareceu do pensamento 
sociológico internacional, provavelmente pela inexistência de novas traduções para a língua inglesa, já que não é mencionado no estado-da-arte sobre o tema (cf. Edmunds \& Turner, 2002).

20. Em uma nova edição de 1960, Marías adicionou um apêndice com uma reflexão sobre a teoria das gerações até o século XIV desenvolvida pelo pensador árabe Ibn Khaldoun, o único autor não europeu incluído no circuito. Seu livro foi traduzido posteriormente para o inglês (1967) e para o italiano. Em 1968, o autor escreveu o verbete "geração" na International Encyclopedia of the Social Sciences.

\section{O modelo,} preferido por Ortega y Gasset é o do sociólogo alemão Helmut Schelsky, que publicou em 1957 o livro Die Skeptische Generationen (A geração cética), no qual reuniu os resultados de diferentes trabalhos sobre os valores do jovem alemão da década anterior.

22. Três campos de pesquisa podem ser divididos da seguinte forma: 1. em primeiro lugar, os estudos sobre a transição da infância uma geração e ao uso heterodoxo da noção de geração, que estaria segundo o autor - desaparecendo em favor de uma visão mais complexa da diversidade juvenil. ${ }^{21}$

\subsection{Gerações nas pesquisas contemporâneas sobre juventude}

Em 1989, Marías publicou uma nova edição ampliada sob o título de Generaciones y constelaciones, na qual, no ápice da sistematização do método analítico das gerações, reflete sobre a chamada "geração conflito" pós68. Para este autor, a noção deve ser aplicada somente às "gerações decisivas" nos termos de Ortega y Gasset, ou seja, àquelas que marcam um ponto de inflexão, mas não para qualquer diferença geracional:

Eu acredito que o fenômeno não contamina com rigor as gerações, mas sim a idade: ela pode ser chamada de idade conflito. A distância anormal refere-se à fase juvenil de cada geração, não para a geração como um todo, somente para a juventude que passou, que não volta a ser nem particularmente inovadora nem diferente (1989: 13).

Desde meados dos anos 1960, a teoria das gerações foi posta de lado no pensamento sociológico por ser considerada conservadora e antiquada, sendo substituída pelas teorias neomarxistas que consideraram os jovens como uma "nova classe" (Campany, 1968) e centralizaram na "revolta cultural dos jovens" (De Miguel, 1972). No entanto, desde 1985 o conceito de gerações tem sido "redescoberto" pelas novas gerações de pesquisadores espanhóis, que o estão retomando para reler e repensar as concepções clássicas a partir de Aranguren até Ortega y Gasset.

Isto não está desconectado do acesso ao poder de uma nova geração política, em 1982, e que proclamou a si mesma como herdeira de 1968, utilizando-se deste argumento para destituir as gerações anteriores e bloquear o caminho das gerações seguintes durante duas décadas. A mesma coisa aconteceu na América Latina, onde a transição para a democracia em países como a Argentina, o Chile e o México foram vividas por uma "geração conflito" que alimentou a redescoberta de clássicos (que, neste caso, embalaram as "revoluções" juvenis do início do século XX). A teoria das gerações é atualmente tão importante como sempre, apesar de não ter ainda "gerado" uma atualização de suas bases teóricas e metodológicas. ${ }^{22}$ 
para a vida adulta, com base na distinção entre coorte geracional e curso da vida, que renovaram os métodos da sociologia empírica; 2. em seguida, a recuperação da memória histórica da II República Espanhola e da Guerra Civil, dos momentos em que os movimentos juvenis foram protagonistas, por meio da utilização da história oral; 3. por fim, a emergência da geração em rede e de uma cultura global, renovando a prática dos estudos culturais (cf. Feixa e Porzio, 2005).

Ao contrário da geração 68 , a geração atual é definida por fatores cosmopolitas. Isso é ilustrado com base em três "constelações geracionais": 1. a geração migratória (marcada pelos processos de migração transnacional); 2. a geração aprendiz (marcada pelo trabalho precário); e 3. a geração colcha de retalhos (marcada por processos de hibridização cultural). Nestas três áreas (demográfica, econômica e cultural), a geração mais jovem (ou qualquer de suas frações) atua como um barômetro das novas tendências.

De um outro ponto de vista, é importante destacar que a emergência de sociedades - como a que se destaca atualmente nos países ocidentais onde várias gerações adultas estão presentes na cena social - suscita uma série de novos e prementes problemas, especialmente em relação a redistribuição justa da riqueza e, juntamente com isso, a necessidade de definição de um novo contrato social entre gerações mais velhas e mais novas (Begston \& Achenbaum, 1993).

A queda na taxa de natalidade e o aumento na expectativa média de vida traz consigo, juntamente com o envelhecimento da população, novas desigualdades no que diz respeito ao relacionamento que as pessoas têm com o mundo do trabalho e a divisão de recursos públicos entre as gerações. De 
fato, essas desigualdades assumem formas concretas, especialmente ao longo das linhas geracionais. Neste contexto, como aponta Alessandro Cavalli (1994), os conflitos são potencializados, por exemplo, no funcionamento do mercado de trabalho, nas características do sistema de pensão e na acumulação da dívida pública. Todos esses fatores, de várias maneiras e formas, destacam as diferentes oportunidades que as gerações têm no presente - e, provavelmente, terão no futuro - de obtenção de acesso ao poder e manutenção de recursos simbólicos materiais.

No entanto, paralelamente a este lado mais sombrio para o relacionamento entre gerações, há também um lado bom que não pode ficar sem pelo menos alguma menção aqui. Esta faceta positiva revela os traços das novas formas de solidariedade que estão surgindo hoje entre as gerações. Assim, por exemplo, apesar da tendência em escala europeia de as gerações conviverem sob um mesmo teto menos tempo que no passado (com a exceção conhecida dos jovens na região do Mediterrâneo), os laços de afetividade entre as gerações não parecem estar enfraquecendo. Novas formas de "intimidade à distância" (Bengston \& Achenbaum, 1993) são estabelecidas, acompanhadas de práticas concretas destinadas a reequilibrar as disparidades entre as gerações por meio de intercâmbios privados e materiais (heranças, doações, pequenas contribuições monetárias) ou imaterial (relativa, por exemplo, ao intercâmbio de tempo). Esta complexa rede de práticas, caracterizada por um elevado grau de reciprocidade, dirige-se tanto das gerações mais velhas para as mais jovens quanto na direção oposta (Attias-Donfut \& Renaut, 1994).

Não menos significativo é o apoio oferecido em relação à questão do planejamento para o futuro - uma exigência existencial que, como a pesquisa mostra, é de natureza particularmente problemática para os jovens de hoje (Leccardi, 2005).

Abstract: Since August Compte and Karl Mannheim (but also since José Ortega y Gasset and Antonio Gramsci), the concept of generation has been a relevant topic in social sciences and humanities. As a metaphor for the social construction of time, it has been one of the most influential categories, not only in the theoretical debate but also in the public effects of youth research. Even if the uses and abuses of the concept are rooted in the European context during the period between I and II World War, it has been relevant in the ideological and political debates of other regions. This paper is an attempt to rethink the concept of generation from an historical perspective, pointingout its relevance for contemporary youth debates.

Keywords: generation, youth, sociology, Italy, Spain. 


\section{Referências}

Abrams, Ph. (1982). Historical sociology, Shepton Mallet: Open Books.

Aranguren, J. L. (1969). La juventud europea y otros ensayos, Barcelona: Seix Barral [1961].

AтtAS-Donfut, C. (1988). Sociologie des générations. L'empreinte du temps, Paris: PUF.

- (1991). Générations et âges de la vie, Paris: PUF.

Attias-Donfut, C. \& Renaut, S. (1994). "Vieillir avec ses enfants", Communications, n. 59, pp. 21-35.

Bauman, Z. (2007). "Between us, the generations", in J. Larrosa (ed), On generations. On coexistence between generations, Barcelona: Fundació Viure i Conviure, pp. 365-376.

BeCK, U. \& BeCK-GeRnsheIM, E. (2008). Generación global, Barcelona: Paidós [Global Generation, Frankfurt, 2007].

Bengston, V. L. \& Achenbaum, W. A. (1993). The changing contract across generations, Nova York: Aldine De Gruyter.

BeLL, V. (1999). Feminist imagination. Genealogies in feminist theory, Londres: Sage.

BERGER, B. M. (1960). “How long is a generation?", British Journal of Sociology, II, 5, pp. 10-23.

Bourdieu, P. (1979). La distinction. Critique sociale du jugement, Paris: Minuit [Distinction. A social critique of the judgement of taste. Cambridge, Mass.: Harvard University Press, 1984].

Cavalu, A. (1991). "Lineamenti di una sociologia della memoria", in P. Jedlowski \& M. Rampazi (eds), Il senso del passato, Milão: Angeli, pp. 34-43.

— (1994). "Generazioni”, Enciclopedia delle Scienze Sociali, Vol. IV, pp. 621-635. 
CHISHOLM, L. (2002). "Mannheim revisited: Youth, generation and life-course", paper presented at the ISA World Congress, Brisbane, Opening Session in honour of Karl Mannheim.

- (2005). "Generations of knowledge. Knowledge of generations and the generation of knowledge". Keynote contribution to the International Conference Childhoods 2005, Oslo.

Comte A. (1998). Cours de philosophie positive, Vol. 1-2, Paris: Hermann [The positive philosophy, Sunrise, FL.: AMS, 1987] [1830-1842].

Dilthey, W. (1989). "Introduction to the Human Sciences", in idem, Selected works, Vol. I, Princeton: Princeton University Press [ "'Einleitung in die Geisteswissenschaften", in idem, Gesammelte Schriften, Band 1, , Leipzig, 1914] [1883].

Edmunds, J. \& TuRner, B. S. (2002). Generations, culture and society, Buckingham: Open University Press.

EISENSTADT, S. N. (1964). From generation to generation, Nova York: The Free Press.

FeixA, C. \& Porzio, L. (2005). "Golfos, pijos, fiesteros. Studies on Youth Cultures in Spain 1960-2004", Young, 13 (1), pp 89-113.

FEUER, L. (1968). The conflict of generations, Londres: Heinemann.

Foucault, M. (1971). "Nietzsche, la généalogie, l'histoire", in idem, Dits et écrits, Vol. 2. Paris: Gallimard, pp. 120-155 ["Nietzsche, genealogy, history", in idem, Language, counter-memory, practice. Selected essays and interviews, edited by D. F. Bouchard, Ithaca: Cornell University Press, 1977, pp. 138-164].

Gramscl, A. (1975). "La questione dei giovani", in idem, Quaderni del carcere, Torino: Einaudi ("The question of the young", in idem, Prison notebooks, Notebook 1, Nova York: Columbia University Press] [1949].

HALBWACHS, M. (1975). Les cadres sociaux de la mémoire, Paris/La Haye: Mouton [1925]. 
JANSEN, N. (1977). La teoría de las generaciones y el cambio social, Madri: EspasaCalpe [Generation theory, Pretoria: University of South Africa, 1975) [1975].

Jedlowskı, P. (1994). Il sapere dell'esperienza, Milão: il Saggiatore.

Kertzer D. E. (1983). "Generation as a sociological problem”, Annual Review of Sociology, n. 9, pp. 187-209.

LaRrosa, J. (ed) (2007). On generations. On coexistence between generations, Barcelona: Fundació Viure i Conviure.

LeCCARDI, C. (2005). "Facing uncertainty. Temporality and biographies in the new century", Young. 13(2), pp. 123-146.

- (2006). "Family memory, gratitude and social bonds", in J. A. Parker, M. Crawford \& P. Haims (eds), Time and memory, Leiden/Boston: Brill, pp. 279-302.

Maffesolı, M. (2007). "Tribalism and hospitality", in J. Larrosa (ed), On generations. On coexistence between generations, Barcelona: Fundació Viure i Conviure, pp. 377-379.

Mannheim, K. 1993. "El problema de las generaciones", Revista Española de Investigaciones Sociológicas (REIS), n. 62, pp. 145-168 ["Das Problem der Generation", in Wissenssoziologie. Auswahl aus dem Werk, hg. von Kurt H. Wolff, Neuwied/Berlin: Luchterhand, 1964, pp. 509-565; "The Problem of Generations", in Essays on the sociology of knowledge, edited by P. Kecskemeti, Nova York: Routledge \& Kegan Paul, 1952, pp. 251-273] [1928].

MARíAs, J. (1968). "Generations", in International Encyclopedia of the Social Sciences, Vol. 6, pp. 88-92.

(1989). Generaciones y constelaciones, Madri: Alianza [Generations: A historical method, Alabama University Press, 1970] [1949].

MeAd, M. (1977). Cultura y compromiso. El mensaje a la nueva generación, Barcelona: Granica [Culture and comitment, Nova York: The Free Press, 1970). [1970].

Mendel, G. (1972). La crisis de las generaciones. Barcelona, Península (La crise des générations, Paris, Seuil, 1969]. 
Michon, P. (2002). "Strata, blocks, pieces, spirals, elastics and verticals: Six figures of time in Michel Foucault", Time \& Society, 11(2/3), pp. 163-192.

Moskvichov et alii (1979). La sociedad y la sucesión de las generaciones, Moscou: Progresso.

Namer, G. (1988). "Affectivité et temporalité de la mémoire", L’homme et la Societé, n. 4, pp. 21-35.

Ortega y Gasset, J. (1966). "La idea de las generaciones", El tema de nuestro tiempo, Obras completas, Vol. 3, Madri: Revista de Occidente, pp. 145-156 [The modern theme, Nova York: Harper \& Row, 1961] [1923].

- (1970). "El método histórico de las generaciones", En torno a Galileo, Obras completas, Vol. 5, Madri: Revista de Occidente, pp. 11-71 [Man and crisis, Nova York: Allen \& Unwin, 1959] [1933].

-(1996). "Juventud, cuerpo", in Meditaciones de nuestro tiempo. Las conferencias de Buenos Aires 1916-1928, México: FCE, pp. 207-228 [1928].

Roszak, T. (1973). El nacimiento de una contracultura, Barcelona, Kairós [The making of a counter culture, Nova York: Doubleday, 1968/1969) [1968].

SÁnCheZ de la YNCERA, I. (1993). "La sociología ante el problema generacional", Revista Española de Investigaciones Sociológicas (REIS), n. 62, pp. 147-191.

SCHELSKY, H. (1957). Die skeptische Generation, Düsseldorf: Eugen Diederich Verlag.

SIEBERT, R. (1991). É femmina però è bella. Tre generazioni di donne al Sud, Turim: Rosenberg \& Sellier.

TAPSCOTT D. (1998). Growing up digital: The rise of the net generation, Nova York: McGraw-Hill. 